\title{
THE ROLE OF HEALTH SYSTEMS IN THE INDIAN AND GLOBAL CONTEXT
}

\author{
Preeti Soni and Manish Pant
}

\section{Introduction}

Climate change leads to significant challenges for the health sector as it brings additional health concerns, demanding a concrete response from the sector. Climate change impacts health systems in various ways - infrastructural damage due to extreme flooding and precipitation, the rising burden of diseases, and disrupted supply chains leading to shortages of drugs and other medical commodities, to name a few. Health systems must be robust in order to meet increasing demands, and resilient so that they may survive the impacts of climate change. As healthcare providers and healthcare facilities are on the frontline, they need to be appropriately strengthened. In poorer countries, the already weak human resource structures and inadequate financing for health could stretch the health system to breaking point unless they undergo preparation to become climate-resilient. This chapter deals with:

1. The connections between climate change and health systems, providing an overview of the interlinkages and examining health systems using two case studies.

2. The need to address climate change and health issues in an integrated manner.

\section{The impact of health systems on climate change}

Health systems cause stress on the environment through their consumption of large quantities of energy, water and materials, and their generation of considerable emissions and waste. In the health sector, hospitals are the largest contributors to carbon emissions, accounting for 39\% of the sector's total in the United States (Chung and Meltzer, 2009). Hospitals need all-day use of medical devices for sterilisation, medical and laboratory services; and equipment for heating, cooling, computing, refrigeration, laundry and food services. Hospitals also generate greenhouse gas (GHG) emissions associated with waste disposal and transportation. Other contributors to the overall carbon footprint of health systems are the prescription drugs sector 
$(14 \%)$, physician and dental services (13\%), equipment $(12 \%)$ and nursing homecare services (8\%) (Chung and Meltzer, 2009).

Healthcare delivery has grown significantly over the years. Increasing incomes, ageing populations, epidemiological transition and advanced technologies have led to healthcare contributing to a higher percentage of national GDPs, ranging from $17 \%$ in the USA to $3.5 \%$ in India (World Bank data (n.d.)). Health systems of most countries, particularly in the developed world, have become large and energy-intensive in the twenty-first century. For example, in the United States, hospitals are the second-most energyintensive users after the food industry (USEIA, 2012). It is evident that as healthcare expenditures increase, the energy consumption in this sector will increase. Coupled with the contribution from consumption of other resources, materials and chemicals, this will add significantly to the carbon footprint.

\section{Health carbon footprint}

Estimating the health carbon footprint (HCF) is not easy or straightforward, as health services represent an outcome of the cumulative $\mathrm{CO}_{2}$ emissions of its proximal components. These include infrastructure, technology, transport, manufacturing processes, supply chains, etc. In absolute terms, India's health sector is the seventh-largest emitter of $\mathrm{CO}_{2}$ after China, USA, European Union (EU), Japan, Russia and Brazil, as seen in Table 2.1. However, its emission per capita and its $\mathrm{HCF}$ as a percentage of national CF is lower than others. In all these countries, domestic emissions contribute over $70 \%$ of the total HCF. The main sectors in healthcare contributing to $\mathrm{CO}_{2}$ emissions include sectors associated with heating, water and electricity consumption and those associated with transport. Approximately $10 \%$ of the $\mathrm{CO}_{2}$ emissions also directly occur in the pharmaceutical and chemical sectors (Pichler et al., 2019).

Table 2.1 HCF in absolute terms, per capita and as a percentage of overall CF

\begin{tabular}{lccc}
\hline Country & HCF $(M t)$ & HCF/Cap $(t)$ & Share of CF $(\%)$ \\
\hline USA & 547 & 1.72 & 7.6 \\
CHINA & 342 & 0.25 & 3.0 \\
EU & 249 & 0.49 & 4.7 \\
JAPAN & 103 & 0.81 & 6.4 \\
RUSSIA & 76 & 0.53 & 4.0 \\
BRAZIL & 44 & 0.21 & 4.4 \\
INDIA & 39 & 0.03 & 1.5 \\
\hline
\end{tabular}

Source: Pichler, Peter-Paul \& Jaccard, Ingram \& Weisz, Ulli \& Weisz, Helga. (2019). International comparison of healthcare carbon footprints. Environmental Research Letters. 14. doi: 10.1088/1748-9326/ab19e1. 


\section{Determinants of health carbon footprint}

HCF is a reflection of the national Carbon Footprint, as GHG emissions and expenditure (GDP) are linked. Three key determinants of HCF are:

1. Carbon intensity of the domestic system - defined as $\mathrm{CO}_{2}$ emission as a part of total final energy consumption (TFC)

2. Energy efficiency of national economy - defined as a ratio of TFC to GDP, and

3. National healthcare expenditure per capita

More specifically, the determinants of HCF include a myriad of services, processes and products that contribute to GHG emissions. The Greenhouse Gas Protocol Initiative is a global, multi-stakeholder partnership of governments and non-governmental organizations that has established accounting and reporting standards for accepted GHGs. These standards are used by various organizations including those in healthcare and classify emissions under three categories (called Scopes).

Scope 1 - Direct GHG Emissions from the activities of an organization that are under their control, including fuel combustion in owned and controlled gas boilers, fleet vehicles, furnaces, air-conditioning, etc.

Scope 2 - Indirect GHG Emissions from the generation of purchased electricity consumed by the health sector. These emissions physically occur at the facility where electricity is generated even though they drive energy consumptions at other locations.

Scope 3 - Other Indirect GHG Emissions from activities of the healthcare sector, occurring from sources that it does not own or control, including transportation, procurement and supply chains, waste management, etc. Scope 3 has the greatest share of emissions in the health sector (HCWH and Arup, 2019).

Figure 2.1 demonstrates the relationship between the three scopes and how they combine to produce GHGs.

Since its climate impact is so vast, the health sector can play a major role in mitigation efforts around the world. Health systems need to use efficient technologies and waste management techniques that can contribute to GHG mitigation efforts. The most efficient way to reduce HCF is by decoupling domestic energy systems from healthcare expenditure. For this to occur, national health systems should transition to greener options that reduce GHG emissions while maintaining a high quality of health services. This includes better designed and energy-efficient buildings that deploy low energy-consuming technologies for heating and cooling, and energy-saving medical equipment. In addition, global and national partnerships must be 


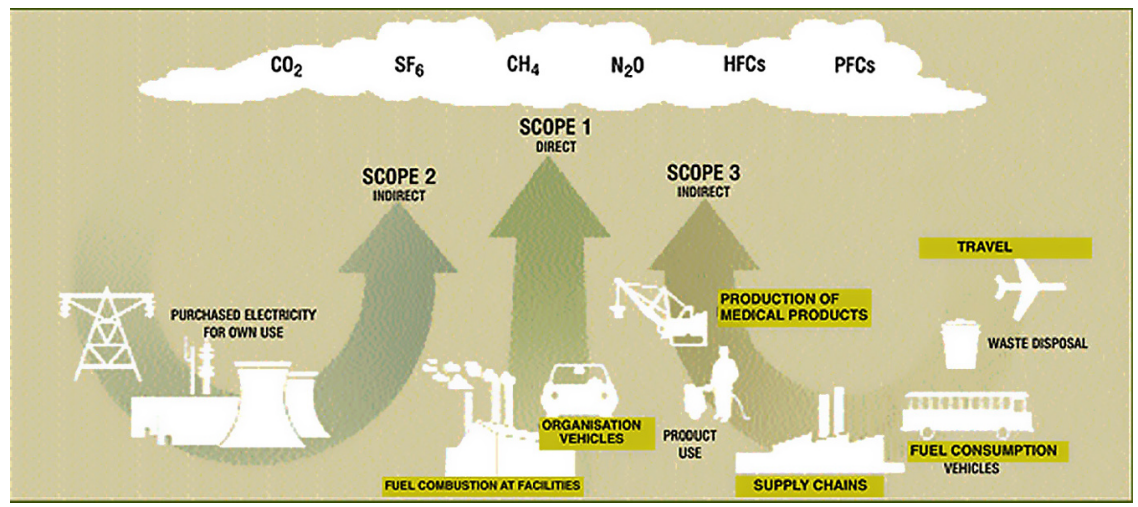

Figure 2.1 Emissions across a value chain in the health sector.

Source: World Resources Institute and World Business Council for Sustainable Development (2004). The greenhouse gas protocol: A corporate accounting and reporting standard. Revised edition. https://ghgprotocol.org/sites/default/files/standards/ghg-protocol-revised.pdf.

created in order to work towards developing a greener and sustainable production and supply chain for medical products.

\section{The impact of climate change on health systems}

Broadly speaking, climate change impacts the various aspects of a national health system through three overarching pathways that are interlinked:

- Direct impacts - these are caused by extreme weather events like floods or droughts which directly affect health infrastructure, workforce and patient load. Thus, increased mortality and morbidity can be expected due to heatwaves or fires.

- Indirect impacts - these are caused by the environment-mediated effects of climate change leading to higher humidity or variable rainfall such as air pollution, food, water-and vector-borne diseases, etc.

- Socioeconomic impacts - these arise due to disruptions in the social and economic networks of humans leading to reduced food production, large scale migrations, slowing economic growth, and increased poverty.

\section{How can the health sector address climate change?}

The health sector can play an essential part in mitigating the effects of global climate change by taking steps to limit its own significant climate footprint. The World Health Organization has identified seven key 
strategies for health systems to become more climate-friendly, while at the same time, saving money and generating significant health, economic and social co-benefits. Many of these strategies can be implemented by a shift in procurement policies and practices in the health systems and the health sector (PAHO, 2017). Indeed, several initiatives are being taken in hospitals and health systems around the world in this direction.

1. Energy efficiency - reduce hospital energy consumption and costs through efficiency and conservation measures.

2. Green building design - build hospitals that are responsive to local climate conditions and optimised for reduced energy and resource demands.

3. Alternative energy generation - produce and/or consume clean, renewable energy onsite to ensure reliable and resilient operations.

4. Transportation - use alternative fuels for hospital vehicle fleets; encourage walking and cycling to the facility; promote staff, patient and community use of public transport; site healthcare buildings to minimise the need for staff and patient transportation.

5. Food - provide sustainably grown local food for staff and patients.

6. Waste - reduce, re-use, recycle, compost; employ alternatives to waste incineration.

7. Water - conserve water; avoid bottled water when safe alternatives exist.

The collective problems of GHG emissions, local pollution and financial strain are experienced by most health systems around the world, though they may differ in some respects. There are clear co-benefits to mitigation efforts in health systems. The cost of not doing it, in terms of health alone, is enormous. The health sector's energy use and resulting toxic emissions undermine the health of the people they are meant to serve. The United States' health sector uses 73 billion kWh of conventional electricity, adding over US\$ 600 million per year in increased health costs, including asthma, respiratory illnesses and hospital emergency department visits (WHO and Healthcare Without Harm Discussion Draft, 2015). In addition, the United States health sector's 341 trillion BTUs (or British thermal units) for heat and cooling contributes to even more polluting emissions, adding billions of dollars more in healthcare bills and hundreds of billions more in indirect costs to society (WHO and Healthcare Without Harm Discussion Draft, 2015). A reduction in energy emissions that also contribute to air pollution will have a widespread impact on human health.

Moreover, the practices that contribute to climate change and undermine public health can also have a serious impact on the financial resources of health systems. For instance, health systems around the world face high energy prices. With the cost of fossil fuels set to increase further in the years to come, conservation, efficiency and alternative energy measures will carry long-term financial benefits (Box 2.1). 


\section{Box 2.1 Case study}

\section{Solar energy for low-emission and resilient health systems}

Using solar energy contributes to improved resilience of health systems as a consistent source of energy, as well as contributing to the reduction of GHG emissions by reducing electricity costs and decreasing the health system's carbon footprint. In India, Primary Health Centers (PHCs) and/or Community Health Centers (CHCs) are largely responsible for the last mile delivery of healthcare services at the village level. They form the base of the government-funded public health system. Many PHCs/CHCs face the challenge of inadequate infrastructure and unreliable or even absent power supply, affecting their capability to provide effective healthcare services. In remote areas, stand-alone diesel-powered generators are used for powering PHCs, backed up by kerosene lamps, candles or flashlights. Generators, however, are expensive to operate, as well as maintaining and adding to emissions.

Under a GEF-GOI-UNDP project, the strengthening of rural health systems has been supported by using solar energy. The project helped demonstrate the use of solar energy by installing solar rooftop photovoltaic systems in the facilities to improve their performance and cost-effectiveness. In the state of Jharkhand, nine battery-backed roof-top solar systems were installed on nine CHCs in rural areas as pilot projects to demonstrate the viability and benefits under the project. It was demonstrated that an average $6-10 \mathrm{kWp}$ solar plant with a storage system can help meet basic critical power requirements (regular power supply and running most critical medical equipment during power cuts). If replicated across all CHCs, it is estimated that $3.20 \mathrm{MW}$ of rooftop solar systems would be installed in the rural and peri-urban healthcare segment alone, which will generate $5045 \mathrm{MWh}$ per annum and abate $4844 \mathrm{tCO} 2$ every year, along with providing continuous power supply for effective healthcare service delivery.

Source: GOI-UNDP programme "Improving Healthcare through Reliable Supply of Solar Energy in selected CHCs across Jharkhand" under the Project on "Market Transformation and Removal of Barriers for Effective Implementation of the State Level Climate Change Action Plans." The project aims to reduce GHG emissions achieved through the implementation of renewable energy and energy efficiency solutions in the states of Jharkhand and Manipur. 


\section{The health sector's response to the effects of climate change: building resilient health systems}

Climate change threatens to undermine several gains made in the health sector which will negatively impact the achievement of Universal Health Coverage (UHC) and the United Nation's Sustainable Development Goals (SDG) overall. It can have unpredictable and complex effects on health systems; underprepared systems will find it very difficult to respond to climate shocks in the future. The World Health Organization defines climate resilience in the health sector as one that can "anticipate, respond to, cope with, recover from and adapt to climate-related shocks and stress, so as to bring sustained improvements in population health, despite an unstable climate" (WHO, 2015).

The WHO describes the essential elements of a resilient health system as laid out in Table 2.2 (WHO, 2015). These elements are interlinked across

Table 2.2 Framework for a climate-resilient health system

\begin{tabular}{|c|c|c|}
\hline $\begin{array}{l}\text { Building } \\
\text { Blocks }\end{array}$ & Components & Key Interventions \\
\hline $\begin{array}{l}\text { Leadership and } \\
\text { Governance }\end{array}$ & $\begin{array}{l}\text { Leadership and } \\
\text { Governance }\end{array}$ & $\begin{array}{l}\text { Policies that prioritise integrated } \\
\text { approaches to climate change and } \\
\text { healthcare management of } \\
\text { emergencies. }\end{array}$ \\
\hline $\begin{array}{l}\text { Human } \\
\text { Resources for } \\
\text { Health }\end{array}$ & Health Workforce & $\begin{array}{l}\text { Enhance skills and competencies of } \\
\text { health workforce on climate change } \\
\text { and health. Develop communication } \\
\text { plans to improve awareness of various } \\
\text { health professionals on climate change } \\
\text { risks. }\end{array}$ \\
\hline \multirow[t]{3}{*}{$\begin{array}{l}\text { Health } \\
\text { Information } \\
\text { Systems }\end{array}$} & $\begin{array}{l}\text { Vulnerability, } \\
\text { Capacity and } \\
\text { Adaptation } \\
\text { Assessment }\end{array}$ & $\begin{array}{l}\text { Understand the key population risks } \\
\text { around climate change, identify } \\
\text { weaknesses in health systems, conduct } \\
\text { investment case studies to identify } \\
\text { cost-effective programmes and the } \\
\text { interventions needed to respond. }\end{array}$ \\
\hline & $\begin{array}{l}\text { Integrated Risk } \\
\text { Monitoring and } \\
\text { Early Warning }\end{array}$ & $\begin{array}{l}\text { Scale up the use of hazard detection } \\
\text { tools including epidemiological } \\
\text { surveillance and remote-sensing } \\
\text { technologies creating an early-warning } \\
\text { system to better anticipate and } \\
\text { respond to health emergencies. }\end{array}$ \\
\hline & $\begin{array}{l}\text { Health and } \\
\text { Climate } \\
\text { Research }\end{array}$ & $\begin{array}{l}\text { Develop a national agenda using basic } \\
\text { and applied multidisciplinary research } \\
\text { with the aim of identifying climate } \\
\text { risks to health, identifying local } \\
\text { solutions and technologies, and } \\
\text { assessing broader determinants. }\end{array}$ \\
\hline
\end{tabular}

(Continued) 
Table 2.2 (Continued)

\begin{tabular}{|c|c|c|}
\hline $\begin{array}{l}\text { Building } \\
\text { Blocks }\end{array}$ & Components & Key Interventions \\
\hline $\begin{array}{l}\text { Essential } \\
\text { Medical } \\
\text { Products and } \\
\text { Technologies }\end{array}$ & $\begin{array}{l}\text { Climate Resilient } \\
\text { and Sustainable } \\
\text { Technologies } \\
\text { and } \\
\text { Infrastructure }\end{array}$ & $\begin{array}{l}\text { Strengthen health infrastructure through } \\
\text { building codes that address climate } \\
\text { risks such as heat waves, and } \\
\text { improving water and sanitation } \\
\text { facilities to tackle floods. In addition } \\
\text { to essential medicine and diagnostics, } \\
\text { health facilities should be equipped } \\
\text { with antidepressants and } \\
\text { antipsychotics to address the mental } \\
\text { health impact of climate change. }\end{array}$ \\
\hline \multirow[t]{3}{*}{ Service Delivery } & $\begin{array}{l}\text { Management of } \\
\text { the } \\
\text { Environmental } \\
\text { Determinants of } \\
\text { Health }\end{array}$ & $\begin{array}{l}\text { Develop multisector programming } \\
\text { across different ministries reflecting } \\
\text { climate change adaptation and } \\
\text { mitigation strategies. Health can be } \\
\text { integrated into other sectors such as } \\
\text { transport, environment, energy, } \\
\text { housing, etc. }\end{array}$ \\
\hline & $\begin{array}{l}\text { Climate-Informed } \\
\text { Health } \\
\text { Programmes }\end{array}$ & $\begin{array}{l}\text { Various health departments can } \\
\text { integrate climate-informed strategies } \\
\text { for a stronger response; these include } \\
\text { communicable and non-communicable } \\
\text { diseases, water and sanitation, } \\
\text { nutrition, mental health, emergency } \\
\text { healthcare, etc. }\end{array}$ \\
\hline & $\begin{array}{l}\text { Emergency } \\
\text { Preparedness } \\
\text { and } \\
\text { Management }\end{array}$ & $\begin{array}{l}\text { Strengthen national disaster response } \\
\text { systems including mechanisms for } \\
\text { public health emergencies like } \\
\text { outbreaks, extreme weather events } \\
\text { and community preparedness. }\end{array}$ \\
\hline Health Financing & $\begin{array}{l}\text { Climate and } \\
\text { Health } \\
\text { Financing }\end{array}$ & $\begin{array}{l}\text { Increased investments from governments } \\
\text { and external donors like GEF and } \\
\text { UNFCCC are needed to fund } \\
\text { interventions in the above system } \\
\text { elements. }\end{array}$ \\
\hline
\end{tabular}

Source: Adapted from WHO, 2015

six building blocks. Each component needs a set of interventions that contribute to the overall resilience of the health system. A critical component of this framework is increased healthcare financing - both public and private to cost for developing climate-friendly technologies, energy-efficient buildings and infrastructure, and a more skilled and competent health workforce that is knowledgeable on climate crises and efficient service delivery mechanisms. Box 2.2 demonstrates the important and effectiveness of skilled healthcare workers. 


\section{Box 2.2 Case study}

\section{Skilled human resources build resilient health systems}

The Government of India has established a digital platform to manage the vaccine supply chain across all health facilities in the country, called the Electronic Vaccine Intelligence Network (eVIN). A well-trained cadre of health staff is placed in every district, skilled in programme management and the use of digital technology at the last mile. Over 50,000 health workers are trained and retrained on the effective supply chain management of vaccines and where possible, other medical commodities as well. Over a period of time, eVIN has helped streamline and optimise vaccine stock management from national to subdistrict levels. It has also empowered the health workers to dedicate themselves fully to ensure immunisation service delivery at all times.

These digitally skilled workers have played a major role in India's successful rollout of Covid vaccines through the implementation of the CoWIN platform across the country (https://www.cowin.gov.in/). This health workforce has also played a crucial role during monsoon season in ensuring that all vaccine stocks are kept safe in the event of health facilities getting flooded. Using the digital platform, they have been able to plan in advance for the redistribution of vaccine stock in a systematic manner to facilities in non-flooded areas, and to ensure some level of continuity on service delivery when possible. Digitally skilled frontline workers can also serve as building blocks of real-time surveillance for disease outbreaks during disasters, leading to a better and nuanced response by authorities.

Strengthening health systems to address the additional health risks of climate change is critical in order to reduce current and future health burdens. Reducing and managing health risks over the next few decades will require modifying health systems to prepare for, cope with, and recover from the health consequences of climate variability and change (adaptation). Adaptation will be required across the century, with the extent of mitigation being a key determinant of health systems' ability to manage risks projected later in the century (Smith et al., 2014). The most effective vulnerability reduction measures for the health sector in the short term are programmes that implement and improve basic public health measures, such as the provision of clean water and sanitation, securing essential healthcare including vaccination and child health services, increasing capacity for disaster preparedness and response, and alleviating poverty (IPCC, 2014).

Health systems will need to implement measures to help them adapt and cope with the new challenges and risks. Some key steps in this direction should include: 
- Advancing research to enhance understanding of the linkages between climate change and health systems.

- Developing climate risk and vulnerability assessments to identify the health impacts of climate change, as they include both epidemiological and climate data. These assessments can help identify weaknesses in health systems and define strategic response interventions to strengthen the systems.

- Developing and deploying early warning systems to monitor and provide information on the impacts of climate change on the transmission of vector-borne and other diseases.

- Developing emergency preparedness and management plans to ensure that health systems can function during extreme events and to prepare them to cope with economic and social disruption (such as pandemics, migration, food shortages, etc.) from climate change. This can reduce risks, save lives, and minimise the impact of climate emergencies in communities.

- Developing tools in health programming and operations that include current climate variability as well as future projected climate change; these tools are crucial to make health programmes climate-resilient.

Climate change-related actions can affect current and future population health. Overall, the health sector will have to provide leadership in advocating for climate-friendly and resilient health systems in policies, and promoting equity and good governance in national and regional policies. This would also imply the need for

- Strong information systems that collect timely and relevant data on climate-vulnerable populations and regions, and the incidence and geographic range of climate-sensitive health outcomes.

- Human and financial resources to protect individuals and communities from the health impacts of climate change by providing training and capacity building for professionals and the public to support efforts to reduce health risks and providing effective service delivery during crises and disasters.

\section{Key takeaways}

- Health systems cause stress on the environment and add to GHG emissions, resulting in most health systems, nationally and globally, having a high health carbon footprint.

- The health sector can play a major role in mitigation efforts around the world by using efficient technologies and waste management techniques.

- Climate change significantly affects current and future demands and the effectiveness of the health systems. The impacts may be direct, indirect or socio-economic. 
- Healthcare providers and healthcare facilities will be on the frontline and need to be capacitated in dealing with the impacts of climate change.

- There are a number of strategies to strengthen the resilience of health systems and reduce their climate footprints, of which two have been demonstrated using case studies.

\section{References}

Chung, J. W., \& Meltzer, D. O. (2009). Estimate of the carbon footprint of the US health care sector. Journal of the American Medical Association, 302(18), (1970-1972).

Health Care Without Harm \& Arup. (2019). Health care's climate footprint. Green paper number one. https://noharm-global.org/

IPCC. (2014). Summary for policymakers. In Climate Change 2014: Impacts, Adaptation, and Vulnerability. Part A: Global and Sectoral Aspects. Contribution of Working Group II to the Fifth Assessment Report of the Intergovernmental Panel on Climate Change.

PAHO. (2017). Climate change and health (leading by example: Transforming health systems to tackle climate change). https://www.paho.org/salud-en-las-americas2017/mhp-climate.html

Pichler, P.-P., Jaccard, I. S., Weisz, U., \& Weisz, H. (2019). International comparison of health care carbon footprints. Environmental Research Letters, 14(6), 0640004.

Smith, K. R., Woodward, A., Campbell-Lendrum, D., Chadee, D. D., Honda, Y., Liu, Q.,... \& Sauerborn, R. (2014). Human health: Impacts, adaptation, and cobenefits. In C. B. Field, V. R. Barros, D. J. Dokken, K. J. Mach, M. D. Mastrandrea, \& others (Eds.), Climate change 2014: Impacts, adaptation, and vulnerability; Part A: Global and sectoral aspects. Contribution of working group II to the fifth assessment report of the intergovernmental panel on climate change, chapter 11 (pp. 709-754). Cambridge University Press.

World Resources Institute and World Business Council for Sustainable Development. (2004). The greenhouse gas protocol. A corporate accounting and reporting standard. Revised edition. https://ghgprotocol.org/sites/default/files/standards/ghgprotocol-revised.pdf.0

The World Bank. (n.d.) Retrieved on 20 July 2020. https://data.worldbank.org/

U.S. Energy Information Administration. (2012). Commercial buildings energy consumption survey. https://www.eia.gov/consumption/commercial/reports/2012/ energyusage/

WHO. (2015). Operational framework for building climate resilient health systems. W.H.O.

WHO and Healthcare Without Harm Discussion Draft. (2015). Healthy hospitals, healthy planet, healthy people, p. 5. https://www.who.int/docs/default-source/ climate-change/healthy-hospitals-healthy-planet-healthy-people. pdf?sfvrsn=8b337cee_1 